Journal of the

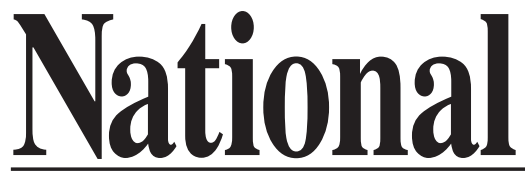

Academy or

Forensic
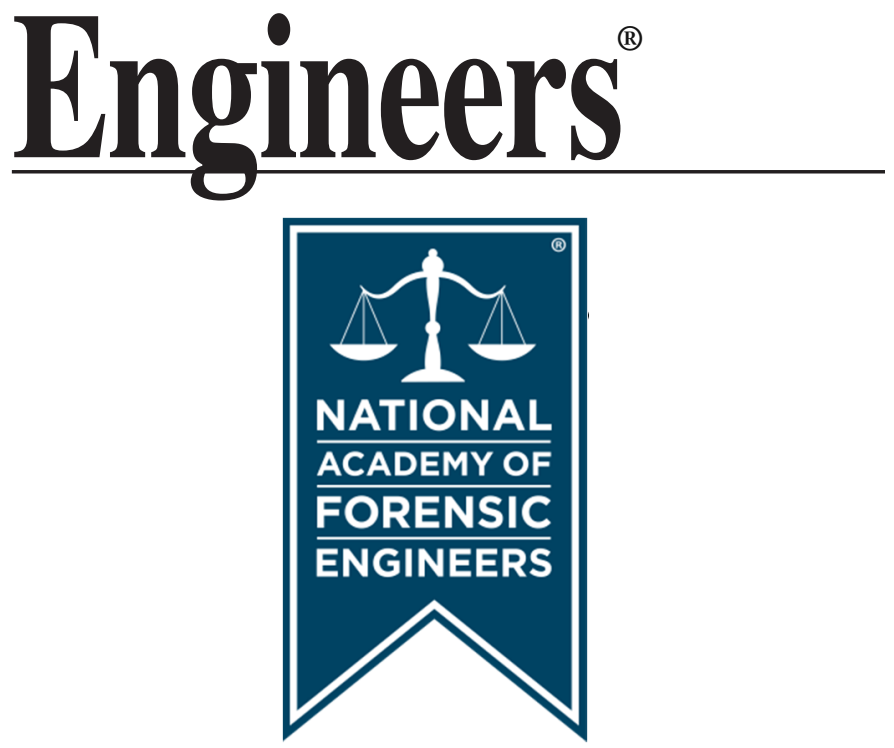

http://www.nafe.org ISSN: 2379-3252 


\title{
Forensic Engineering Analysis of Falling Merchandise in a Retail Warehouse
}

by Wilbur T. Yaxley, P.E., C.S.P. (NAFE 270F)

Jeffrey D. Armstrong, P.E. (NAFE 644S)

\begin{abstract}
This paper discusses a forensic engineering approach to the analysis of falling merchandise incidents in retail warehouses. A discussion of the engi neering and safety analysis of two personal injury incidents caused by falling merchandise is included. The first incident involves a fork-lift pallet that held a stack of lounge chairs, which fell from an overhead shelf, striking a customer. The stack of lounge chairs was an irregular shape that was longer and narrower than the pallet. The chairs were held together with stretch wrap and attached to the pallet with "X-bracing" using cords made of twisted stretch wrap. The placement of the pallet in the overhead shelf, the attachment of the chairs to the pallet, and various safety policies and procedures are analyzed. Various analyses to determine the properties of stretch wrap were performed. A scale model was constructed to assist with the analysis. The second incident involves a rack of vertically stacked lumber that fell forward striking a customer after he had removed one or two boards from the rack and placed them on a cart. The boards, the stacking system, and the restraint system are analyzed. A video re-enactment was prepared to illustrate how the boards fell.
\end{abstract}

\section{Introduction}

Falling merchandise in retail warehouses causes numerous injuries every year, and can occasionally result in death. Lower racks are used to display merchandise for the customer, while overhead racks are often used for storage and warehousing of inventory. Overhead stock may be stored on shelves that are more than twenty (20) feet above the sales floor. When an item falls from such a height, even relatively light items can cause substantial impact forces. 
Copyright @ National Academy of Forensic Engineers (NAFE) http://www.nafe.org. Redistribution or resale is illegal. Originally published in the Journal of the NAFE volume indicated on the cover page. ISSN: 2379-3252

\section{Analytical Procedures}

Forensic engineers can provide valuable assistance in evaluating falling merchandise incidents. The analyses of the engineer could include the following:

- Analysis of stocking procedures

- Analysis of factors contributing to the incident

- Calculation of forces required to cause merchandise to fall from the racks

- Calculation of impact forces

- Review and analysis of internal safety policies and procedures

Research and analysis of accident photographs, eye witness testimony, injured party's testimony, analysis of the location through a site visit, analysis of stocking procedures should be part of the forensic engineering analysis. The forensic engineer should attempt to answer various questions regarding the falling merchandise incident, which might include:

- Were restraining bars and/or cables properly in place?

- Was the use of restraining bars and/or cables appropriate?

- What equipment was used to place merchandise in the shelving?

- Were proper inspection procedures conducted and documented in the incident area preceding the incident?

- Could the incident have been staged?

- What forces would have been required to push, pull, or topple merchandise from the shelves?

- What was in the shelves behind the merchandise on the adjacent aisle?

- Could forces from behind, originating in the adjacent aisle, have caused the merchandise to fall?

- Are the reported injuries consistent with the described incident?

- Was paletized merchandise properly secured to the pallet?

- Did merchandise or packaging overhang the front of the shelving?

- Were proper warnings in place to advise customers not to reach for overhead merchandise?

These procedures and questions were addressed by the forensic engineers in the following incidents. 
Copyright () National Academy of Forensic Engineers (NAFE) http://www.nafe.org. Redistribution or resale is illegal. Originally published in the Journal of the NAFE volume indicated on the cover page. ISSN: 2379-3252

\section{Case Number 1: Falling Lounge Chairs}

While shopping in a retail warehouse center, a customer was looking at merchandise in the lower shelves when a pallet containing a stack of lounge chairs fell from the overhead racks striking him in the back of the head and in the back. While various individuals heard the incident, it appears that there were no witnesses who saw the pallet of lounge chairs fall from the overhead racks. The forensic engineers were provided with fourteen (14) photographs taken at the accident scene by the retail center's safety investigator. Depositions of the customer and of various employees who arrived on the scene shortly after hearing the incident were reviewed. The authors were retained to perform an engineering analysis to determine what might have caused the stack of chairs to fall, and to evaluate safety procedures to determine whether internal or industry standards or practices had been violated.

\section{Description of the Racks}

The lounge chairs were attached to a forklift pallet which was placed in large heavy-duty steel shelves. The shelf that held the pallet of lounge chairs was eight (8) feet above the floor level, having a metal grid shelf surface with the top rails running from front to back. A sticker on the front of the eight-foot shelf that held the lounge chairs indicates "OVERHEAD" above the level of the sticker, and "SALES FLOOR" below that level. The rack that contained the chairs was approximately eight-and-a-half $\left(8 \frac{1}{2}\right)$ feet wide and four (4) feet deep. The total height of the shelving was sixteen (16) feet above the floor. There was no safety cable, safety chain, or safety beam across the front of the rack, and there were no brackets for attaching safety cables on the vertical posts on the sides of this rack.

The back of this rack abutted the back of the rack that faced the adjacent aisle, with an approximate six (6) inch gap between the racks. There was a shelf directly behind lounge chairs approximately a foot-and-a-half $\left(\begin{array}{ll}1 & 1 / 2\end{array}\right)$ to two (2) feet above the surface of the shelf that held the chairs. There were two vertical posts between the two abutting racks, but no horizontal members such as safety cables, chains, or beams separating the two racks to prevent merchandise from the adjacent aisle from falling backward or being pushed into the back of the lounge chairs.

Directly beneath the rack where the pallet of lounge chairs was placed was a shelf containing long, narrow boxes that were lying diagonally in the racks. These boxes were approximately six (6) feet long, and extended approximately twelve (12) to eighteen (18) inches beyond the front of the racks and into the aisle.

\section{Description of the Pallet and Chairs}

A stack of lounge chairs was attached to a pallet commonly used with a forklift. Two lounge chairs bearing the same UPC Number and SKU Number as those 
Copyright @ National Academy of Forensic Engineers (NAFE) http://www.nafe.org. Redistribution or resale is illegal. Originally published in the Journal of the NAFE volume indicated on the cover page. ISSN: 2379-3252

involved in the accident were purchased by the engineers to assist in the engineering analysis of the incident. Each chair weighed approximately 17.8 pounds. The chairs are stacked by placing the arm rests of one chair over those of another. When stacked in this manner, the chairs do not stack vertically, but rather they stack in a manner where the foot end of the top chair extends beyond the foot end of the chair immediately beneath it as shown in Figure 1. When twelve (12) chairs are stacked in this manner, the top chair is offset approxi mately 12 to 14 inches from the bottom chair. The height of the stack of chairs is approximately six (6) feet at the head end of the chairs, and approximately four (4) feet at the foot end of the chairs. The total length of the stack is approximately sevenand-a-half $\left(7 \frac{1}{2}\right)$ feet.

The stack of chairs was attached to a wheeled metal positioning frame on the bottom. The

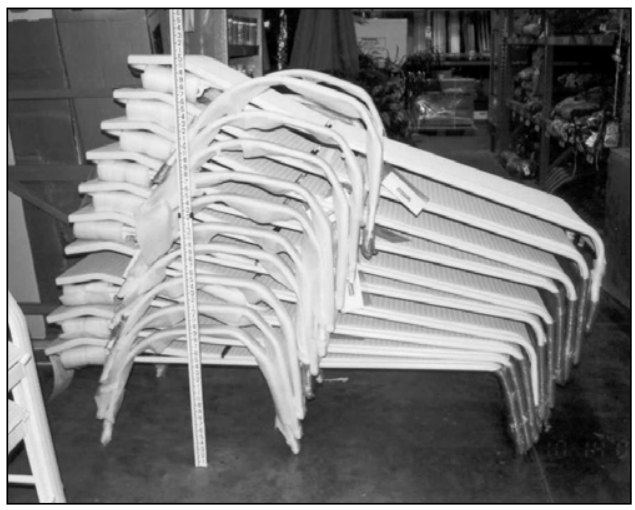

Figure 1

Exemplar stack of lounge chairs.

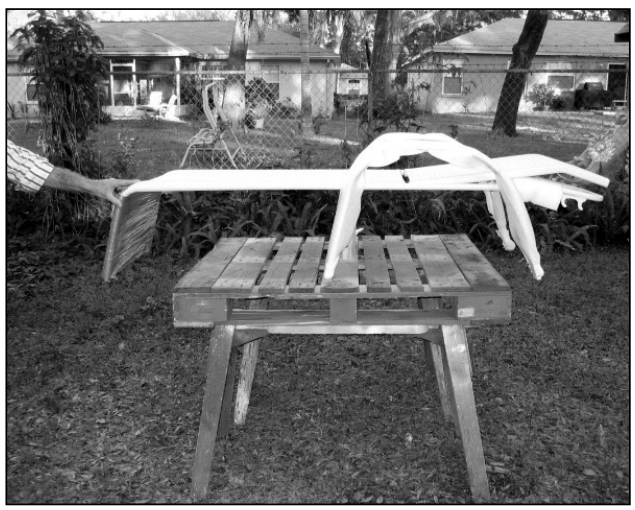

Figure 2

Single lounge chair on fork lift pallet. frame has six (6) swivel wheels (casters) to assist in positioning and moving the entire stack of chairs on the sales floor. The legs of the bottom chair rested in a $\mathrm{u}$-channel in the frame. Risers attached to the frame of the chair for stability. The frame was approximately 28 inches by 66 inches, with the bottom of the frame approximately two (2) inches off the ground. The frame had a caster at each corner, and one (1) on each side of the frame near the center. The corner wheels on each side were approximately 66 inches apart.

The forklift pallet was a standard 40-inch by 48 -inch pallet. The height of a standard pallet is six (6) inches. There are gaps of undetermined widths between the boards on the top of the pallet. An exemplar pallet weighed 64 pounds. Figure 2 illustrates the length of a single lounge chair in comparison to a pallet. Figure 3 shows a scale model representation of the chairs on the pallet, with arrows 
Copyright @ National Academy of Forensic Engineers (NAFE) http://www.nafe.org. Redistribution or resale is illegal.

Originally published in the Journal of the NAFE volume indicated on the cover page. ISSN: 2379-3252

NAFE 270F/644S

ANALYSIS OF FALLING MERCHANDISE

PAGE 99

defining lateral, longitudinal, and vertical directions as referenced in this paper.

The irregular shaped stack of lounge chairs was held together by wrapping the entire stack with stretch wrap. The positioning frame sat on top of the pallet. The chairs rested on the positioning frame. The chairs were placed on the pallet so that the length of the chairs was parallel to the 48-inch side of

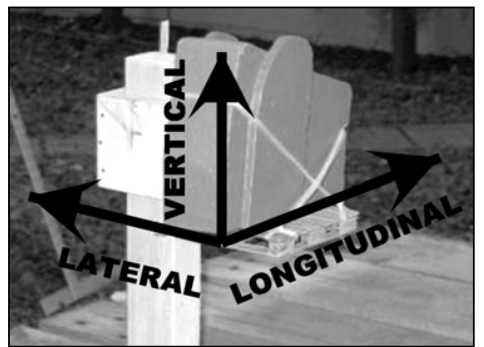

Figure 3 the pallet. When the frame and stack of chairs were placed on the pallet, only the two center wheels rested on the pallet. With the casters at the corners of the frame being approximately 66 inches apart, these corner casters hung over the edge of the pallet. The center wheels may have rested directly on the surface of the pallet, which would have caused the frame and the stack of chairs to wobble, or the wheels may have rested between adjacent boards on the pallet with the frame itself resting directly on the pallet. This would help prevent the load from shift ing on the pallet in the longitudinal direction, but would not keep it from shifting in the lateral direction. The composite stack of chairs overhangs the pallet by approximately 20 inches at both the front and the back. The width of the positioning frame and the stack of chairs (measured at the arm rests) is 28 inches. The width of the pallet is 40 inches. When the chairs are centered on the pallet each side of the stack is six (6) inches from the side of the pallet. Therefore, there is an irregular shaped stack of chairs that is longer than the pallet in one direction, and narrower than the pallet in the other direction sitting on a wheeled position ing frame that does not rest flat across the surface of the pallet.

The stack was attached to the pallet by creating cords from the stretch wrap, tying the cord to the corner of the pallet, wrapping the cord around either the head-end or foot-end of the stack of chairs, and tying it again to the adjacent corner of the pallet. By attaching two (2) stretch wrap cords; one around the head end of the chairs, and one around the foot end; it creates an "X-Bracing" configuration on each side of the stack of lounge chairs. The $\mathrm{X}$-bracing can be seen in the photograph of the scale model in Figure 4. The total unit consisted of twelve (12) lounge chairs, a wheeled metal frame,

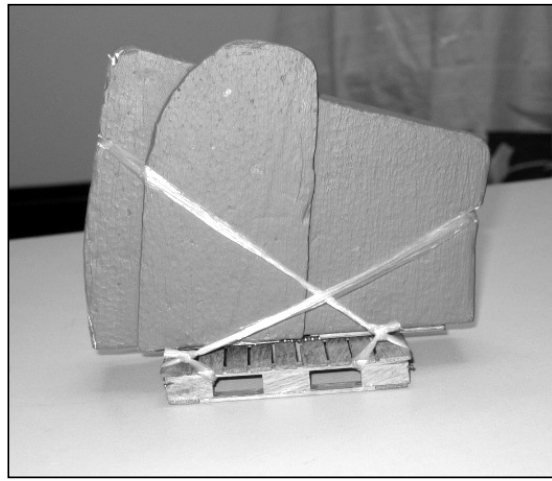

Figure 4

Scale model stack of chairs attached to pallet with stretch-wrap in $\mathrm{X}$-bracing configuration. 
Copyright $\odot$ National Academy of Forensic Engineers (NAFE) http://www.nafe.org. Redistribution or resale is illegal. Originally published in the Journal of the NAFE volume indicated on the cover page. ISSN: 2379-3252

and a forklift pallet held together with stretch wrap. The total height of the stack of chairs, the frame, and the pallet was approximately seven (7) feet at the head end of the chairs, and approximately five (5) feet at the foot end of the chairs. The total weight of the chairs, frame, and pallet was approximately 300 pounds.

\section{Development and Use of the Scale Model}

A scale model was constructed to aid in the analysis and presentation of the incident. The scale model is shown in Figures 5 and 6 , and consisted of the following components:

- Racks (shelving) that held the lounge chairs

- Abutting racks to the rear

- Forklift pallet

- Representative stack of chairs

- Human figure

- Long narrow boxes

- Broom boxes

- Lounge chair cushions

- Cushion display

A not-to-scale representation of a forklift was constructed as seen in Figure 6.

The model was constructed to a scale of $1: 12$. The model was used to evaluate various aspects of the accident, including but not limited to the position of the chairs on the pallet, the Xbracing to hold the chairs to the pallet, the position of the long boxes beneath the pallet of lounge chairs, the position of the plaintiff at the time of the accident, and the location of racks and boxes behind the pallet of lounge chairs.

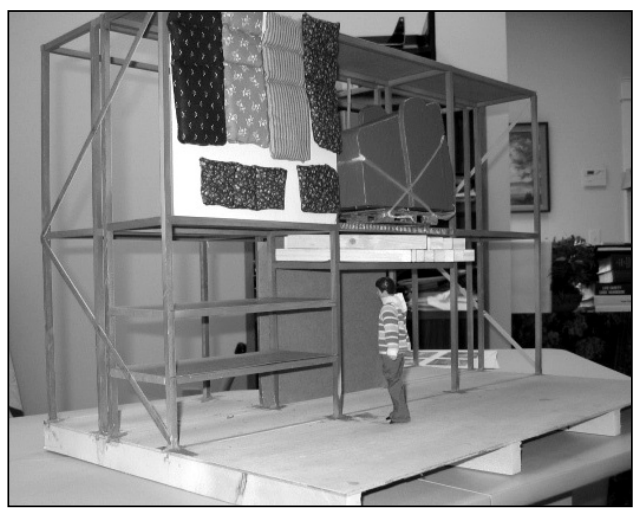

Figure 5

Overall view of scale model with chairs in overhead racks.

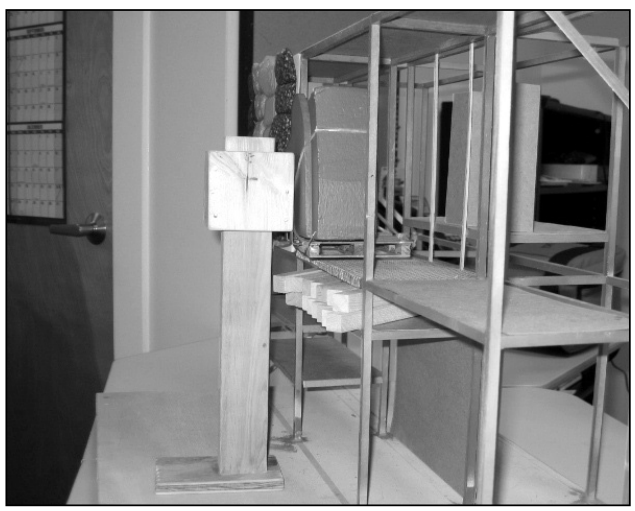

Figure 6

Overall view of scale model. Long boxes beneath chairs interfere with proper placement and viewing of lounge chairs. 
Copyright () National Academy of Forensic Engineers (NAFE) http://www.nafe.org. Redistribution or resale is illegal.

Originally published in the Journal of the NAFE volume indicated on the cover page. ISSN: 2379-3252

NAFE 270F/644S

ANALYSIS OF FALLING MERCHANDISE

PAGE 101

\section{Determination of Pallet Position in Racks}

Based on a review of the available evidence, and through use of the scale model, it was determined that the chairs were attached to a 40 -inch by 48 -inch fork-lift pallet using X-bracing consisting of stretch wrap cords. The length of the chairs was parallel to the 48-inch side of the pallet. The pallet was sitting on an eight (8) foot high, eight-and-a half ( 8 1/2) foot wide, four (4) foot deep rack. The foot end of the chairs was at the left side of the rack, and the head end of the chairs at the right side of the rack. This was determined through an analysis of the accident scene photos and confirmed with the scale model. Our engineering calculations indicated that the front of the pallet was overhanging the front of the shelves by approximately eight (8) to twelve (12) inches. This is consistent with the placement of other pallets in the overhead racks at this store, and at the same chain in other cities.

There were approximately fifteen (15) long narrow boxes in the rack just beneath the rack that contained the stack of lounge chairs as represented in the scale model in Figure 6. It was determined from the photos that these boxes are approximately six (6) feet long based on their angled placement in the racks. They are placed in the racks at an angle to minimize their overhanging the front of the rack.

Behind the rack that held the pallet of lounge chairs is a six (6) inch gap, then a rack that faces the adjacent aisle. There was a shelf approximately nine (9) to ten (10) feet above the floor level directly behind the shelf that held the pallet of lounge chairs. This shelf was used to store boxes of brooms, which were stacked vertically on the shelves.

\section{Analysis of Common Stretch Wrap Material}

The stack of lounge chairs was attached to the forklift pallet with X-bracing consisting of "cords" made from stretch wrap material. Analyses were performed to understand the characteristics of stretch wrap when it is formed into a cord and used to secure items to the pallet. Stretch wrap cords are placed in tension when a segment of the cord is pulled at each end so that it stretches. The amount of tensile force in the cords relates directly to the amount of force that the cords apply to the stack of lounge chairs and the pallet in order to hold them together.

An analysis was performed to determine whether the tensile forces in a stretch wrap cord decrease with time due to relaxation of the material. It was determined that when stretched approximately 50 percent beyond its initial unstretched length, the initial tensile forces in the stretch wrap cord gradually decrease for several hours until the tension has been reduced by approximately twenty (20) to twenty-five (25) percent. For example, if a cord is initially stretched until the tension in the cord reaches fifteen pounds, and the length of 
Copyright @ National Academy of Forensic Engineers (NAFE) http://www.nafe.org. Redistribution or resale is illegal. Originally published in the Journal of the NAFE volume indicated on the cover page. ISSN: 2379-3252

the cord is then kept constant, the force may be reduced to approximately eleven (11) to twelve (12) pounds after several hours. This suggests that when the stack of lounge chairs was attached to the pallet with the X-bracing by stretch wrap cords, the initial forces that were intended to hold the stack of chairs to the pallet had been reduced by approximately twenty (20) to twenty-five (25) percent by the time the incident occurred.

An analysis was performed to determine the amount of stretching of cords required to generate various tensile forces within the cords. It was determined that under small tensile forces the stretch wrap cords stretch very little. As tension in the cords is increased the rate of stretching increases. The samples that were analyzed stretched approximately ten (10) to twelve (12) percent beyond the initial unstretched length with tension forces of approximately twelve (12) pounds. With a tension of fourteen (14) pounds, the cords stretched approximately 23 to 24 percent beyond their initial unstretched length. With a tension of eighteen (18) pounds, the cords stretched more than 50 percent beyond their initial unstretched length. It was also observed that with the tension kept constant, the cords con tinue to stretch for several minutes after the tension is applied to the cords.

It was observed that the stretch wrap material is "clingy" or sticky. This property allows the stretch wrap to cling or adhere to itself similar to common kitchen plastic wraps. However, this property makes it somewhat difficult to tie a knot in a stretch wrap cord as it tends to adhere to itself as the end of the cord is pulled through a loop in the knot. This would have made it difficult to tie the stretch wrap cords to the corners of the forklift pallet while maintaining the ten sion in the cords after wrapping around the stack of lounge chairs.

\section{Tensile Forces in Stretch Wrap X-brace Cords}

The effectiveness of the X-bracing configuration shown in Figure 4 used with the lounge chairs was evaluated. With the stretch wrap cords capable of maintaining a constant stretched tension of approximately ten (10) to twenty (20) pounds, the amount of tension that was applied by the X-brace cords in the longitudinal (parallel to the lounge chairs), lateral (perpendicular to the lounge chairs), and vertical (up and down) directions was calculated. Table 1 summarizes the longitudinal forces, lateral forces and the vertical forces that were provided by the stretch wrap cords for a range of tensile forces of ten (10) to twenty (20) pounds in the cords if the chairs are centered on the pallet. Longitudinal forces resist movement of the chairs on the pallet from front to back. Lateral forces resist movement of the chairs on the pallet from side to side. Vertical forces hold the chairs down to the pallet. The calculation of longitudinal, lateral, and vertical forces are provided for both the upper cord (around the head-end of the chairs) and the lower cord (around the foot end of the chairs) is shown in the table. 
Copyright @ National Academy of Forensic Engineers (NAFE) http://www.nafe.org. Redistribution or resale is illegal Originally published in the Journal of the NAFE volume indicated on the cover page. ISSN: 2379-3252

\begin{tabular}{|l||c|c|c||c|c|c|}
\hline \multicolumn{1}{|c|}{ TABLE 1: Force Components in Stretch Wrap Cords - Chairs Centered on Pallet } \\
\hline \multicolumn{1}{|c||}{} & \multicolumn{3}{|c||}{ Upper Cord } \\
\hline $\begin{array}{c}\text { Cord } \\
\text { Tension } \\
\text { (Pounds) }\end{array}$ & $\begin{array}{c}\text { Longitudinal } \\
\text { Force } \\
\text { (Pounds) }\end{array}$ & $\begin{array}{c}\text { Lateral Force } \\
\text { (Pounds) }\end{array}$ & $\begin{array}{c}\text { Vertical Force } \\
\text { (Pounds) }\end{array}$ & $\begin{array}{c}\text { Longitudinal } \\
\text { Force } \\
\text { (Pounds) }\end{array}$ & $\begin{array}{c}\text { Lateral Force } \\
\text { (Pounds) }\end{array}$ & $\begin{array}{c}\text { Vertical Force } \\
\text { (Pounds) }\end{array}$ \\
\hline \hline 10 & 7.1 & 0.7 & 7.1 & 8.7 & 0.8 & 4.9 \\
\hline 12 & 8.5 & 0.8 & 8.5 & 10.4 & 1.0 & 5.9 \\
\hline 14 & 9.9 & 1.0 & 9.9 & 12.1 & 1.2 & 6.9 \\
\hline 16 & 11.3 & 1.1 & 11.3 & 13.9 & 1.3 & 7.8 \\
\hline 18 & 12.7 & 1.3 & 12.7 & 15.6 & 1.5 & 8.8 \\
\hline 20 & 14.1 & 1.3 & 14.1 & 17.4 & 1.7 & 9.8 \\
\hline
\end{tabular}

It is notable that depending on the overall tension, each cord provides from 7 to 17 pounds of longitudinal force to resist movement of the chairs from front to back on the pallet, while providing from just 0.7 to 1.7 pounds in the lateral direction to resist movement of the chairs from side to side. This shows that the $\mathrm{X}$-bracing using the stretch wrap material is inadequate to secure the stack of chairs to the pallet due to the inability of this configuration to resist the lateral forces which would prevent lateral movement of the stack of chairs on the pallet.

With the stretch-wrap cords providing only minimal resistance to lateral movement, it is probable that the wheeled stack of chairs rolled to the edge of the pallet during transport with a forklift or reach truck. Fork lift operators typically tilt the forks back once a load is picked up to ensure the load is not dropped during transport and stocking. If this happened, the wheel of the positioning frame could have slipped off the edge of the pallet, preventing the chairs from returning to the center of the pallet. This would have moved the center of mass closer to the front of the pallet, and would have changed the tension in the stretch-wrap cords. Table 2 provides a summary of the lateral, longitudinal, and vertical forces in the cords when the chairs have shifted to the front edge of the

\begin{tabular}{|c||c|c|c||c|c|c|}
\hline \multicolumn{1}{|c|}{ TABLE 2: Force Components in Stretch Wrap Cords - Chairs at Edge of Pallet } \\
\hline \multicolumn{1}{|c||}{} & \multicolumn{3}{|c||}{ Upper Cord } & \multicolumn{3}{c|}{ Lower Cord } \\
\hline $\begin{array}{c}\text { Cord } \\
\text { Tension } \\
\text { (Pounds) }\end{array}$ & $\begin{array}{c}\text { Longitudinal } \\
\text { Force (Pounds) }\end{array}$ & $\begin{array}{c}\text { Lateral Force } \\
\text { (Pounds) }\end{array}$ & $\begin{array}{c}\text { Vertical Force } \\
\text { (Pounds) }\end{array}$ & $\begin{array}{c}\text { Longitudinal } \\
\text { Force (Pounds) }\end{array}$ & $\begin{array}{c}\text { Lateral Force } \\
\text { (Pounds) }\end{array}$ & $\begin{array}{c}\text { Vertical Force } \\
\text { (Pounds) }\end{array}$ \\
\hline \hline 10 & 6.9 & 2.0 & 6.9 & 8.5 & 2.2 & 4.8 \\
\hline 12 & 8.3 & 2.4 & 8.3 & 10.2 & 2.6 & 5.8 \\
\hline 14 & 9.7 & 2.8 & 9.7 & 11.9 & 3.1 & 6.7 \\
\hline 16 & 11.1 & 3.1 & 11.1 & 13.6 & 3.5 & 7.7 \\
\hline 18 & 12.5 & 3.5 & 12.5 & 15.3 & 3.9 & 8.6 \\
\hline 20 & 13.9 & 3.9 & 13.9 & 17.0 & 4.4 & 9.6 \\
\hline
\end{tabular}


Copyright @ National Academy of Forensic Engineers (NAFE) http://www.nafe.org. Redistribution or resale is illegal. Originally published in the Journal of the NAFE volume indicated on the cover page. ISSN: 2379-3252

pallet. The table shows that the longitudinal and vertical forces are approximately the same whether the chairs are centered on the pallet or if they have been moved to the edge of the pallet. However the lateral forces in the cords increase to provide from 2.0 to 4.4 pounds of force to resist side to side movement of the stack of chairs on the pallet. This increase in tension is only for the cords on the side of the chairs that is farther from the edge of the pallet. The cords on the front of the pallet where the side of the stack of chairs has moved to the edge lose their tension as the chairs move closer to the edge.

If one of the cords stretches one (1) inch, it will allow 7 to 8 inches of movement in the lateral direction. With the edge of the stack of chairs just six (6) inches from the edge of the pallet when the stack is centered on the pallet, a stretching or increase in the length of each cord of the X-bracing of less than one (1) inch (increase in length of less than 1.5 percent), will allow lateral (side to side) movement of the stack of chairs to the edge of the pallet. Conversely, movement of one (1) inch in the lateral direction will stretch the cord less than one tenth of an inch. Again, this suggests that the X-bracing using the stretch wrap material is inadequate to secure the irregular shaped stack of chairs to the pallet due to the inability of this configuration to resist the lateral forces which would resist movement of the stack of chairs on the pallet from side to side. This is especially true with this load that does not have a flat surface resting on the pallet which would develop a friction bond with the pallet.

\section{Forklift Placement of Pallet in Racks}

The forklift or reach truck that placed the pallet of lounge chairs in the overhead racks would most likely have inserted his forks into the pallet in the lateral direction (from the side). With the pallet loaded onto the forklift from the side, there would be just enough room for the forklift operator to carry the approxi mately seven (7) foot wide load down the eight (8) foot aisle. Once the forks are placed in the pallet, the operator typically would have lifted the pallet a few inches off the ground, then tipped the forks back toward the forklift to prevent the pallet and the load from falling off the front of the forks.

With the X-bracing using the stretch wrap cords providing very minimal lateral force to resist side to side movement of the stack of chairs on the pallet, the wheeled positioning frame and the chairs slid laterally across the pallet toward the forklift when the mast and the forks were tipped back. The frame and the chairs stopped sliding on the pallet when they reached the mast of the forklift. At this point, the front (closest to the forklift) center caster on the frame may have slipped off the front of the pallet. If this happened, the front of the frame may have been lower than the back of the frame, causing the frame and the stack of chairs to tilt forward. When placed in the racks, the entire stack of chairs, including the frame, was sitting on the front edge of the pallet, possibly tilting forward, rather than being centered and upright on the pallet. 
Copyright $@$ National Academy of Forensic Engineers (NAFE) http://www.nafe.org. Redistribution or resale is illegal.

Originally published in the Journal of the NAFE volume indicated on the cover page. ISSN: 2379-3252

NAFE 270F/644S

ANALYSIS OF FALLING MERCHANDISE

PAGE 105

The forklift or reach truck operator would have encountered problems placing the pallet on the eight-foot rack due to the presence of the long boxes that extended out beyond the front of the racks approximately twelve (12) to eighteen (18) inches. The mast of the forklift would have struck the corner of the boxes, preventing the forklift from maneuvering close enough to the racks to place the pallet completely on the shelf. Damage to the corners of the long boxes that stick out the farthest can be seen in the accident scene photos, and provide evidence of possible contact from the forklift. These boxes would also have impeded the view of the shelves, making it difficult for the operator to determine whether the pallet had been placed completely within the racks. Engineering calculations suggest that the pallet was placed on the shelf so that the front of the pallet extended approximately six (6) to twelve (12) inches beyond the front of the rack, with the stack of chairs sitting at the front (closest to the aisle) of the pallet. The overhanging pallet may have been less noticeable during routine inspections than it might otherwise have been due to the overhanging long boxes directly beneath it.

\section{Analysis of Possible Explanations for Falling Pallet}

Various possible causes and contributing factors to the incident were evalu ated. Various accident scenarios were considered. While it was not determine which scenario was most probable, it is important to note that under every scenario, if the stack of lounge chairs and the pallet had been placed completely within the racks in accordance with published company safety guidelines, the incident could not have occurred. No reasonable force could have been applied to push, pull or tip the stack from the racks. The inadequate X-bracing with stretch wrap cords was a contributing factor as it allowed the chairs to slide laterally (side to side) to the front of the pallet, moving the center of gravity of the composite stack closer to the front. This section summarizes our analysis of various scenarios.

\section{Impact From Behind by Falling Box}

Directly behind and slightly above the rack that contained the stack of lounge chairs was a shelf that contained a box of brooms lying on its side, and at least two (2) tall boxes placed vertically within the rack. There was no safety cable or horizontal member across the back of the rack to prevent vertically stacked merchandise from falling back or being pushed into the adjacent rack. If something caused one of these boxes to tip over into the rack with the stack of chairs, the box could strike the stack with enough force to cause the stack of chairs to tip over and fall into the customer aisle. This would occur with the pal let overhanging the front of the rack and with the chairs positioned on the front of the pallet. This scenario would cause the chairs and the attached pallet to tip over and fall off the front of the rack. With the customer standing in the aisle looking at merchandise below the lounge chairs, the stack of chairs would strike 
Copyright @ National Academy of Forensic Engineers (NAFE) http://www.nafe.org. Redistribution or resale is illegal. Originally published in the Journal of the NAFE volume indicated on the cover page. ISSN: 2379-3252

his head and back as they fell. This scenario would not be possible if there had been a properly placed safety cable or horizontal safety beam across the front or the back of the rack. A restraining device at the back of the rack would have prevented a box from the adjacent rack from falling toward the stack of chairs. A restraining device across the front of the rack would have prevented the stack of chairs from falling, even if it had been struck by a box from the back. The incident could not have occurred in this fashion if the pallet had been placed completely within the racks, and if the stack of chairs were centered on the pallet.

\section{Constant Force From Box Leaning Against Chairs}

A modification of the above scenario could occur if a box from the rack behind fell against the stack of chairs while the pallet was being placed in the racks by the forklift. The impact force would not tip the chairs due to the pallet's engagement with the forklift. The pallet would be placed in an overhanging position, with the stack of chairs at the front of the rack. The box, leaning against the back of the stack of chairs, would apply a constant force on the stack toward the front of the rack. Over time, this constant force would stretch the X-bracing cords on the back side of the pallet, allowing movement of the stack in the lateral (side to side) direction. The X-bracing with stretch wrap cords is an inefficient means of resisting the lateral forces on the stack of chairs, and just a small amount of stretching of the cords can result in significant lateral movement. The application of such a force over time could cause gradual movement or leaning of the chairs, eventually causing the stack of chairs to fall from the front of the racks, without any input from customers or employees at the time of the incident. This is a reasonable scenario, and could explain what caused the stack of chairs to fall from the overhead racks. This scenario would not be possible if there had been a safety cable or horizontal safety beam across the front or the back of the rack. A restraining device at the back of the rack would have prevented a box from the adjacent rack from falling toward the stack of chairs. A restraining device across the front of the rack would have prevented the stack of chairs from falling, even if it had been struck by a box from the back. The incident could not have occurred in this fashion if the pallet had been placed completely within the racks, and if the stack of chairs were centered on the pallet.

\section{Chairs Pushed Over From Behind}

If boxes or other items were being moved or placed within the rack behind the stack of lounge chairs, it is possible that a box or other object could have been pushed past the back of the rack and into the stack of chairs with no barrier to prevent intrusion from the shelf behind. With the pallet overhanging the front of the rack, and the chairs at the front of the pallet, a force could be applied to the stack of chairs that would cause it to tip from the racks. This scenario would not be possible if there had been safety cables or horizontal safety beam across the front or the back of the rack. A restraining device at the back of the rack would have pre 
Copyright () National Academy of Forensic Engineers (NAFE) http://www.nafe.org. Redistribution or resale is illegal.

Originally published in the Journal of the NAFE volume indicated on the cover page. ISSN: 2379-3252

NAFE 270F/644S

ANALYSIS OF FALLING MERCHANDISE

PAGE 107

vented a box from the adjacent rack from falling toward the stack of chairs. A restraining device across the front of the rack would have prevented the stack of chairs from falling, even if it had been struck by a box from the back. The incident could not have occurred in this fashion if the pallet had been placed completely within the racks, and if the stack of chairs were centered on the pallet.

\section{Chairs Pulled Down if Placed Completely Within the Racks}

An analysis was performed to determine the slip coefficient between the shelf surface and the pallet to be approximately 0.41 to 0.50 . If the pallet were placed completely within the racks, with the chairs centered on the pallet, then a constant horizontal force of approximately 125 to 150 pounds would be required to pull the pallet and the stack of chairs more than 20 inches, causing them to fall from the racks. It is not reasonable that a customer or employee could have applied that magnitude of horizontal force eight (8) feet above the floor over the necessary distance to cause the chairs to fall. Additionally, forces provided by environmental factors such as boxes falling or tipping over from behind would not be sufficient to cause the stack of chairs to tip or fall if they were properly placed in the racks. If the chairs had been placed completely within the racks, the stack of chairs would not have fallen into the customer aisle.

\section{Customer Pulls Chairs Down From the Racks (Staged Accident)}

In order for a customer to pull the stack of chairs down from the racks, he must apply enough horizontal force eight (8) feet above the floor to slide the pallet forward until the center of mass extends beyond the front of the racks causing the stack to fall. There was no reasonable manner in which a customer could slide the pallet of chairs toward the front of the racks by pulling the stack with a constant force of 125 to 150 pounds. The pallet and the chairs could be tipped from the rack by applying a sufficient downward force to the front edge of the pallet if it is overhanging the front of the racks. A downward force would not tip the chairs if the pallet is placed completely within the racks. With the chairs at the front edge of the pallet, and the pallet extending seven (7) inches beyond the front of the racks, a downward force of 205 pounds would be required to tip the pallet and chairs from the racks. This means that a person weighing 205 pounds or more could hang from the front of the pallet and cause it to tip from the racks. With eight (8) inches of overhang, a downward force of 142 pounds is required, and with nine (9) inches of overhang a downward force of 92 pounds is required to tip the chairs from the racks.

While a customer could potentially apply enough downward force to the overhanging pallet to tip the chairs from the racks, it is not a reasonable scenario. The customer would need to climb the racks to the left of where the pallet was placed, hang onto the rack with one hand, reach out to his right with the other hand approximately one-and-a-half $\left(1 \frac{1}{2}\right)$ to two (2) feet to grab the edge of the 
Copyright @ National Academy of Forensic Engineers (NAFE) http://www.nafe.org. Redistribution or resale is illegal. Originally published in the Journal of the NAFE volume indicated on the cover page. ISSN: 2379-3252

pallet, and then apply enough downward force to tip the chairs from the racks. The lower racks to the left which the customer would have had to climb were full with cushions which did not appear to have been disturbed by climbing activities. Above the eight (8) foot level, to the left of the stack of chairs, there was a display board of various patio chair cushions that would have interfered with a customer's ability to hang onto the racks while climbing and pulling the pallet down.

The customer reported injuries to the back of his head and to his back. He reported that when he was struck by the chairs he was knocked to the floor, injuring his right knee as it hit the floor. If a customer positioned himself to be able to somehow pull the chairs from the racks, the chairs would strike the customer in the front rather in the back, perhaps knocking him backward. If the customer were standing on the edge of a shelf after climbing the racks, the falling chairs would strike the front of the customer and most likely cause him to fall from the racks. Based on this analysis, it is not likely for a customer to have pulled the pallet and the stack of chairs from the overhead rack and receive impact injuries to the back of the head and the back.

\section{Impact of Safety Devices and Placement in the Racks}

None of the scenarios would have occurred if there had been a properly positioned safety cable, safety chain, or safety beam across the front of the rack in accordance with company policy. None of the scenarios would have occurred if the pallet had been placed completely inside the racks. Each scenario would be less likely if the chairs were centered on the pallet rather than at the front edge of the pallet. Proper placement of safety a safety cable, chain, or beam across the back of the rack would have prevented several of the scenarios.

\section{Analysis of Safety Procedures}

Various industry and in-house safety procedures were reviewed, and we observed the following violations that may have contributed to the incident:

- Merchandise must be placed completely within the shelving, and should not overhang the front of the shelves.

- Wheeled merchandise should not be placed in the overhead shelves.

- Restraining bars or safety cables should be used to secure vertically stacked merchandise.

- No provision was provided for preventing storage in the shelf behind and slightly above the lounge chair shelf from falling toward the lounge chair package

- The chairs were not properly secured to the pallet

- Stretch-wrap is not a reasonable material to secure irregular-shaped and/or wheeled merchandise to the pallet 
Copyright () National Academy of Forensic Engineers (NAFE) http://www.nafe.org. Redistribution or resale is illegal.

Originally published in the Journal of the NAFE volume indicated on the cover page. ISSN: 2379-3252

\section{Opinions Related to Falling Lounge Chairs}

Based on the forensic engineering analysis, the following opinions and conclusions regarding this incident were developed:

- The primary cause of this incident was the improper placement of the pallet of lounge chairs in the overhead racks in such a manner that the pallet extended beyond the front of the racks. If the pallet had been placed completely within the racks, the pallet and the stack of lounge chairs would not have fallen from the overhead racks to the sales floor.

- A contributing factor to this incident was the inadequate method of securing the irregular shaped stack of lounge chairs and positioning frame to the pallet using X-bracing with stretch wrap cords. This provided inadequate lateral support to the stack of chairs, allowing the stack to move from side to side during transport and placement in the racks.

- This incident would not have occurred if a properly placed safety cable, safety chain, or safety beam had been used to keep the chairs in the racks.

- There was no safety cable, safety chain, safety beam, or other safety or restraining device at the back of the racks to prevent intrusion from behind from the adjacent racks.

- Possible external forces that could have caused the pallet and lounge chairs to fall from the overhead racks include, an impact from behind by a falling box, a constant prolonged force caused by a box from behind that fell against the stack during placement in the racks, and a tipping force from behind. These scenarios can only occur if the pallet is placed so that it overhangs the front of the racks. All of the scenarios are more likely if the chairs are sitting at the front edge of the pallet. None of these scenarios would have caused the chairs and pallet to fall if properly placed restraining devices had been used.

- There is no reasonable force that could have pushed or tipped the chairs from the overhead racks if they had been placed completely within the racks.

- The presence of long boxes in the rack beneath the lounge chairs inhibited the proper placement of the pallet and chairs in the overhead rack.

- The customer could not have reasonably climbed the racks and applied sufficient force to tip the stack of chairs from the racks.

- If the customer had somehow pulled the pallet and chairs from the racks, he would have been struck in his front, and not on the back of his head and on his back. 
Copyright @ National Academy of Forensic Engineers (NAFE) http://www.nafe.org. Redistribution or resale is illegal.
Originally published in the Journal of the NAFE volume indicated on the cover page. ISSN: $2379-3252$

\section{Falling Lumber Incident}

A customer at a home improvement store was shopping for rough-cut cedar boards. The 3/4" × 6" x 8' boards were stacked vertically in the lumber bin, and were reportedly packed in tightly. At the back of the bin, a 2" x 4 " board was laid against the back wall so that the bottom of the first board was at least $3 \quad 1 / 2$ inches (the width of a standard 2" x 4" board) from the back wall of the bin. This creates an incline of approximately two degrees. There was a horizontal restraining bar approximately $8 \frac{1}{2}$ feet above the floor of the lumber bin.

The customer reported that he removed the first board from the bin and placed it on a lumber cart. He removed a second board from the bin and turned to place it on the lumber cart. As he was placing the second board on the cart, the remaining boards in the bin fell over on him causing injuries. We were provided with the customer's deposition transcript that described the incident and photographs of the accident location. We visited the accident location to observe the lumber racks, and visited other locations with similar lumber storage and display systems.

The forensic engineer was retained to determine whether the boards could have fallen as described, and to determine what factors contributed to the lumber falling. We purchased approximately twenty (20) boards for analysis and reenactment of the incident. Our investigation showed that the boards that fell were light and flexible. Each board possessed some warping so that when stacked vertically against each other, each board acted as a "spring" or a "bow" against the adjacent boards. With the boards stacked tightly in the bin, each board acted as a "spring" which was slightly compressed. Additionally, the warping of the boards caused the incline to be reduced with each board in the stack until the front boards were nearly vertical. One or two boards in front were leaned against the stack with greater incline to hold the remaining boards in place.

The incident was re-enacted by stacking boards vertically, with the bottom of the back board separated from the wall by a 2 " by 4 " board. The re-enactment revealed that even when the boards were stacked at an incline there was a tendency for them to "spring apart" once the first boards were removed. It was determined that if the back board was placed less than approximately four inches away from the back of the bin that the boards could fall approximately two to four seconds after the front boards were removed, due to the decompression of the warped boards. Our re-enactment of the incident was video-taped and shown at mediation. Sequential photographs of the re-enactment are shown in Figure 7. 
Copyright $\odot$ National Academy of Forensic Engineers (NAFE) http://www.nafe.org. Redistribution or resale is illegal.

Originally published in the Journal of the NAFE volume indicated on the cover page. ISSN: 2379-3252

Our forensic engineering analysis revealed the following:

- The plaintiff's description of the falling incident was reasonable and possible

- Stacking the boards too tightly compresses them so that when the front boards are removed, the remaining boards can then decompress and fall forward.

- If the boards are stacked with an insufficient incline they can fall forward

- The restraining bar was 6 inches higher than the top of the boards. A proper restraining bar would have prevented the incident.
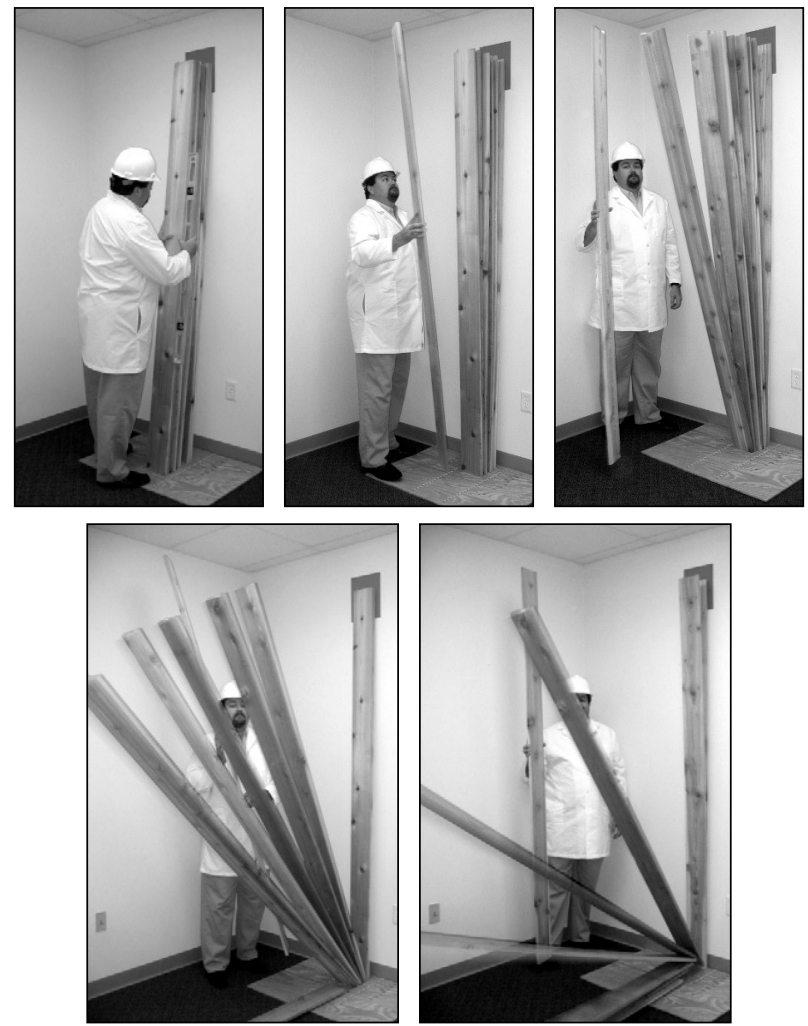

Figure 7 
Copyright @ National Academy of Forensic Engineers (NAFE) http://www.nafe.org. Redistribution or resale is illegal.

Originally published in the Journal of the NAFE volume indicated on the cover page. ISSN: 2379-3252

\section{Conclusion}

The forensic engineering analysis of falling merchandise incidents requires research and creativity. The use of scale model or full-size re-enactments may be required. It is important for the forensic engineer to consider all possible scenarios and contributing factors, including the possibility of a staged incident. Injuries should be reviewed for consistency with the described incident. Safety policies and procedures should be reviewed, and an analysis conducted to determine whether they were followed.

\section{References}

Manual of Safety Practice: A Code of Safety Practices for the Use of Industrial and Commercial Steel Storage Racks . American National Standards Institute, MH16.2-1996. 